\title{
Colon-targeted protein delivery by using solid lipid nanoparticles
}

\author{
Raditya Iswandana* (D), Sutriyo Sutriyo, Maxius Gunawan, Sekar Arum Larasati, Fathia Amalia Putri \\ Laboratory of Pharmaceutics and Pharmaceutical Technology, Faculty of Pharmacy, Universitas Indonesia, Depok, Indonesia.
}

\begin{tabular}{l}
\hline ARTICLE INFO \\
\hline Received on: $04 / 05 / 2021$ \\
Accepted on: $23 / 07 / 2021$ \\
Available online: $05 / 09 / 2021$
\end{tabular}

Key words:

Colon-targeted, drug delivery system, lipid nanoparticle, protein, solid lipid nanoparticles.

\begin{abstract}
Recently, therapeutic proteins have been used to combat life-threatening diseases. To date, oral routes have been developed to deliver proteins. Since the proteolytic degradation in the upper gastrointestinal tract frequently occurs, we need a formulation and strategy to protect and deliver protein to the colon. In this research, solid lipid nanoparticles (SLNs) were prepared in eight formulae for colon-targeted delivery with various glyceryl monostearate, Tween 80 , soy lecithin, and polyethylene glycol 6000 concentrations. Bovine serum albumin (BSA) was used for the protein model in the system. All formulae were characterized by their morphology, particle size, polydispersity index (PDI), zeta potential, and entrapment efficiency. The distribution of particle sizes varied between 94.24 and $186.8 \mathrm{~nm}$ and the zeta potential value ranged from -22.8 to $-34.3 \mathrm{mV}$. Formula 4 (F4) showed the best entrapment efficiency of $78.69 \%$ with a particle size of $102.1 \mathrm{~nm}$, PDI of 0.349 , and zeta potential of $-26.1 \mathrm{mV}$. F4 was then coated with Eudragit S100 and measured for its drug release profile in vitro. F4 coated with Eudragit S100 held the drug released in the gastric and released all the BSA in the colon condition. These results indicated that BSA-SLN F4 could be a promising delivery system to obtain optimal colon-targeted parameters.
\end{abstract}

\section{INTRODUCTION}

Due to recent advances in pharmaceutical biotechnology, therapeutic proteins have been used to combat life-threatening diseases (Rehman et al., 2016). Since 2011, the US Food and Drug Agency has developed and approved 62 recombinant proteins to treat several clinical indications, such as cancers, inflammation, exposure to infectious agents, and genetic disorders (Lagassé et al., 2017). These therapeutic proteins are delivered mainly via the parenteral route. The parenteral route has some disadvantages, such as invasiveness, hypersensitivity reaction for some people, and higher cost than other routes. Furthermore, the short plasma half-life and high elimination rate of protein make a repeated injection needed to obtain therapy effect, so nonparenteral routes, such as the oral route, have been developed to deliver protein (Martins et al., 2007).

The oral route to deliver protein has some barriers, especially the bioavailability of the protein. Proteins isare degraded

\section{"Corresponding Author}

Raditya Iswandana, Laboratory of Pharmaceutics and Pharmaceutical Technology, Faculty of Pharmacy, Universitas Indonesia, Depok, Indonesia.E-mail: raditya@farmasi.ui.ac.id by proteolytic enzymes and $\mathrm{pH}$ of stomach and intestine. The limitation of protein to cross cell membranes and its probability of undergoing enzymatic and/or proteolytic degradation in the upper gastrointestinal (GI) tract can be solved by delivering proteins directly to the colon as the release and absorption target area (Akash et al., 2015; Martins et al., 2007). Less proteolytic activity in colon mucosa decreased CYP3A4 activity (Iswandana et al., 2018a). Reduced P-gp expression makes the colon suitable as a systemic absorption site for protein (Date et al., 2016; Rajpurohit et al., 2010). However, the colon's location at the distal end of the GI tract causes the protein to pass the wide ranges of the GI tract's $\mathrm{pH}$, which can make the protein unstable and inactive ( $\mathrm{Lu}$ et al., 2016). Besides that, various conditions and environments during delivery via the GI tract affect the formulation including the $\mathrm{pH}$, enzyme, electrolyte, transit time, and pressure (Iswandana et al., 2017). Using a nanoparticle as a protein carrier can overcome the problem because a nanoparticle is stable in the GI's environment and can protect the encapsulated drug from extreme $\mathrm{pH}$ and enzyme degradation (Lu et al., 2016).

A colon-targeted drug delivery system can be based on $\mathrm{pH}$ changes, enzyme activity by colon bacteria, time system, and nanoparticles. The nanoparticles system approach makes the protein dissolve and become trapped in the nanoparticles matrix. 
In the past few decades, lipid-based drug delivery systems have gained attention due to their biocompatibility and lipophilicity. One of the lipid nanoparticles used for colon-targeted drug delivery systems is solid lipid nanoparticles (SLNs). An SLN delivery system allows for protein release, increasing protein stability, carrying large quantities of protein, and protecting the protein from the first pass effect. Furthermore, SLNs are considered nanoparticles with better cell tolerability with a size of less than 1,000 nm (Irianti et al., 2020).

In this research, Bovine serum albumin (BSA) was used as a protein model incorporated in the SLN by the doubleemulsion method. SLNs were further coated with Eudragit S100, and the in vitro study was carried out to observe the amount of BSA that can reach the colon.

\section{MATERIALS AND METHODS}

\section{Materials}

BSA (Sigma-Aldrich, Saint Louis, MO), glyceryl monostearate (Chemical Point, Oberhaching, Germany), Tween 80 (Brataco, Jakarta, Indonesia), soy lecithin(Unitechem Co., Ltd., Suqian, China), inulin (BENEO-Orafti SA, Oreye, Belgium), polyethylene glycol (PEG) 6000 (NOF Corporation, Tokyo, Japan), Eudragit S100 (Evonik, Bekasi, Indonesia), Lowry reagent, trichloroacetic acid (Merck, Darmstadt, Germany), and Aquadest were acquired.

\section{Colyophilization BSA with inulin}

An inulin solution $(5 \mathrm{mg} / \mathrm{ml})$ was added to the BSA solution $(2 \mathrm{mg} / \mathrm{ml})$ and stirred homogeneously. The mixed solution was placed in a vial and frozen in a freezer at $-80^{\circ} \mathrm{C}$ and then freeze-dried at $0.2 \mathrm{mBar}$.

\section{Preparation of BSA-SLN}

Table 1 shows the formula of BSA-SLN. The method of SLN preparation used in this study was double emulsion. Glyceryl monostearate was melted at $55^{\circ} \mathrm{C}$. Then, soy lecithin, $20 \mathrm{ml}$ of BSA solution $(2 \mathrm{mg} / \mathrm{ml})$, and PEG 6000 were added. The solution was stirred using a T25 digital ULTRA-TURRAX homogenizer (IKA, Kuala Lumpur, Malaysia) for 10 minutes at 10,000 rpm. The emulsion formed was added to the surfactant solution (Tween 80 ) and sonicated for 25 minutes.

\section{BSA-SLN cCoating with Eudragit S100}

An Eudragit S100 solution with a concentration of 5\% $w / v$ was prepared using deionized water. The optimum BSA-SLN formula solution was then added to the Eudragit S100 solution with the same volume. The addition of SLN to the polymer solution was carried out drop by drop with continuous agitation at room temperature $\left(20^{\circ} \mathrm{C}\right)$ for 10 minutes to produce the desired coating (Zhang et al., 2014). The SLN coating results were immediately frozen at $-85^{\circ} \mathrm{C}$ and lyophilized using a freeze-dryer at $-65^{\circ} \mathrm{C}$ condenser temperature and $0.211 \mathrm{mBar}$ pressure for 24 hours.

\section{Characterizations of BSA-SLN}

\section{Particle Size Distribution}

The measures of the mean intensity (Dp) and polydispersity index (PDI) were taken by photon correlation spectroscopy using Zetasizer Nano ZS (Malvern Panalytical, Malvern, UK). Measurements were made on the SLN dispersion in $1: 1,000$ Aquadest at $25^{\circ} \mathrm{C}$ with a scattering angle of $90^{\circ}$.

\section{Zeta Potential}

Zeta potential from the SLN was measured by electrophoretic light scattering using the Zetasizer Nano ZS (Malvern Panalytical, Malvern, UK). Zeta potential measurements were used to determine the physical stability of the SLN and the electric charge on the SLN's surface. Measurements were made on the SLN dispersion in a $1: 1,000$ Aquadest at $25^{\circ} \mathrm{C}$ with a scattering angle of $90^{\circ}$.

\section{Particle Morphology}

The surface morphology of the SLN-Eudragit S100 was seen using a transmission electron microscope (FEI Tecnai G2 20 S-TWIN, Hillsboro, OR). SLN-Eudragit S100 powder was dispersed in distilled water. As many as one drop of the dispersion was dropped on the carbon-coated copper network to form a thin liquid layer (Elmowafy et al., 2017). The layers on the grid were allowed to dry at room temperature. Next, the grid was attached to the instrument, and photos were taken at various magnifications with an Eagle ${ }^{\mathrm{TM}}$ CCD Camera (Shah et al., 2016).

\section{Entrapment Efficiency of SLN}

The entrapment efficiency of BSA in the SLN is determined indirectly by calculating the BSA that is not trapped. The final SLN preparation results were centrifuged at a speed of $12,000 \mathrm{rpm}$. Protein is calculated from the free BSA in the supernatant from the centrifugation result. $1 \mathrm{ml}$ of supernatant was taken, and then the BSA that is not trapped was precipitated using a 10\% TCA solution. The precipitate was then dissolved in $1 \mathrm{ml}$

Table 1. Formulae of SLN containing BSA.

\begin{tabular}{cccccc}
\hline Formulae & BSA-inulin (\%) & GMS (\%) & Tween 80 (\%) & Soy lecithin (\%) & PEG 6000 (\%) \\
\hline F1 & 5.0 & 1.0 & 1.0 & 0.25 & 0.25 \\
F2 & 5.0 & 2.0 & 1.0 & 0.25 & 0.25 \\
F3 & 5.0 & 1.0 & 1.5 & 0.25 & 0.25 \\
F4 & 5.0 & 2.0 & 1.5 & 0.25 & 0.25 \\
F5 & 5.0 & 1.0 & 1.0 & 0.5 & 0.25 \\
F6 & 5.0 & 2.0 & 1.0 & 0.5 & 0.25 \\
F7 & 5.0 & 1.0 & 1.5 & 0.5 & 0.25 \\
F8 & 5.0 & 2.0 & 1.5 & 0.5 & 0.25 \\
\hline
\end{tabular}


deionized water. The BSA in the solution was tested using the Lowry assay. The absorbance was measured at a wavelength of $750 \mathrm{~nm}$ using a microplate reader (VersaMax, Chattanooga, TN). The BSA concentration was calculated by comparing it against a standard curve of known standard BSA concentrations. The percentage of entrapment efficiency was calculated using the following formula:

Entrapment efficiency (\%)

$=\frac{\text { Total amount of drug loaded }- \text { free drug in supernatant }}{} \times 100$ Total amount of drug loaded

\section{In Vitro Drug Release Studies}

The in vitro release studies were carried out by a modified dissolution method using a dialysis membrane. Before use, dialysis bags with a molecular weight cut-off of $100 \mathrm{kDa}$ were immersed in distilled water for 12 hours. Furthermore, $100 \mathrm{mg}$ of optimal SLN formula was suspended in distilled water. One milliliter of the suspension was filled in a dialysis bag. Then, the dialysis bag was put in a beaker glass containing $250 \mathrm{ml}$ of release media operated at $37^{\circ} \mathrm{C}$ using a magnetic stirrer at a speed of 100 $\mathrm{rpm}$. The in vitro release study was carried out in hydrochloric acid media of $0.1 \mathrm{~N} \mathrm{pH} \mathrm{1.2,} \mathrm{phosphate} \mathrm{buffer} \mathrm{pH} 7.4$, and phosphate buffer $\mathrm{pH} 6.8$ that simulate the stomach, small intestine, and colon, respectively (Iswandana et al., 2018b). The time of drug release in the hydrochloric acid medium of $0.1 \mathrm{~N} \mathrm{pH} 1.2$ was observed for 2 hours, in the phosphate buffer media $\mathrm{pH} 7.4$ for 3 hours, and in the phosphate buffer media $\mathrm{pH} 6.8$ for 3 hours.
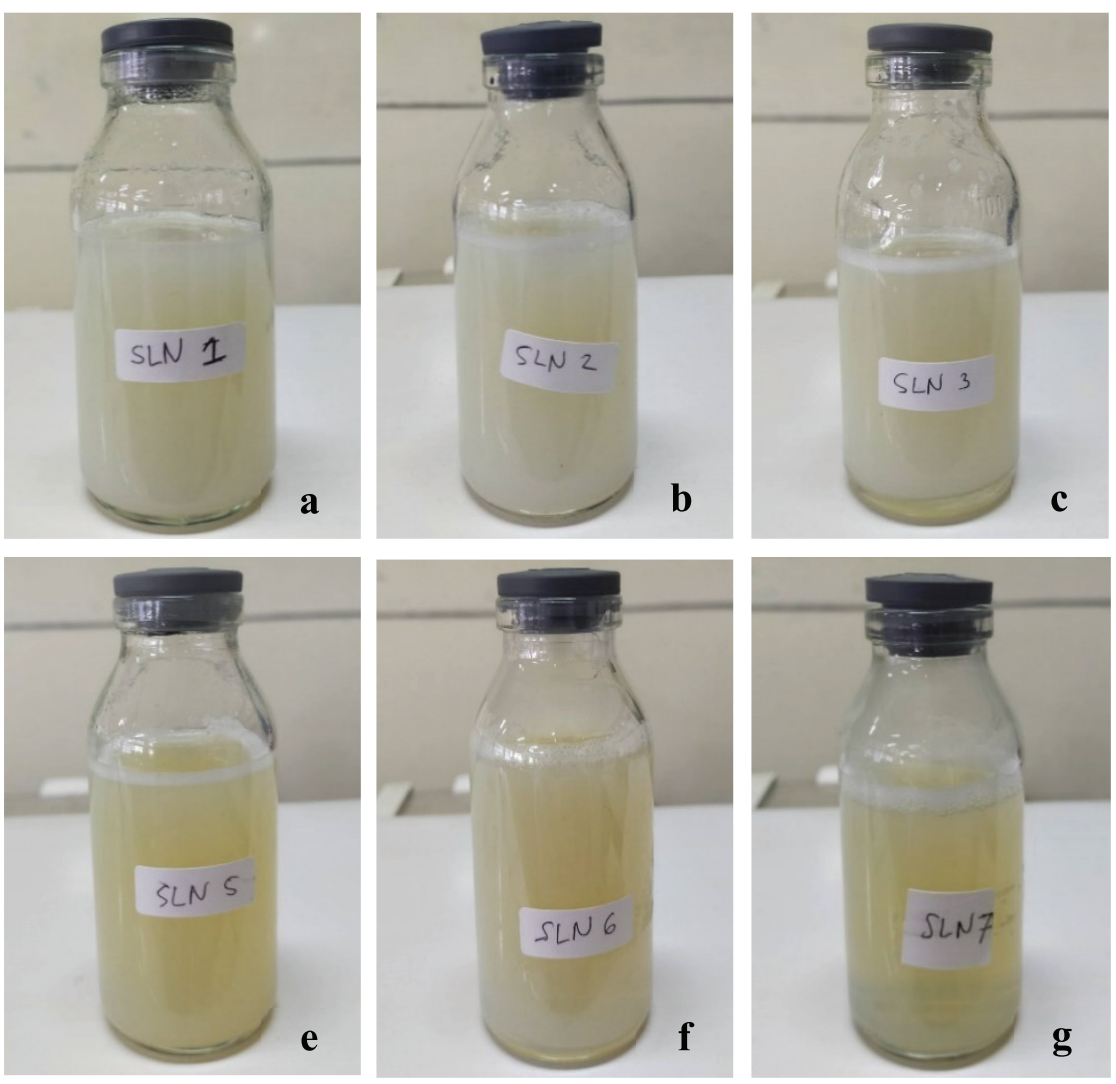
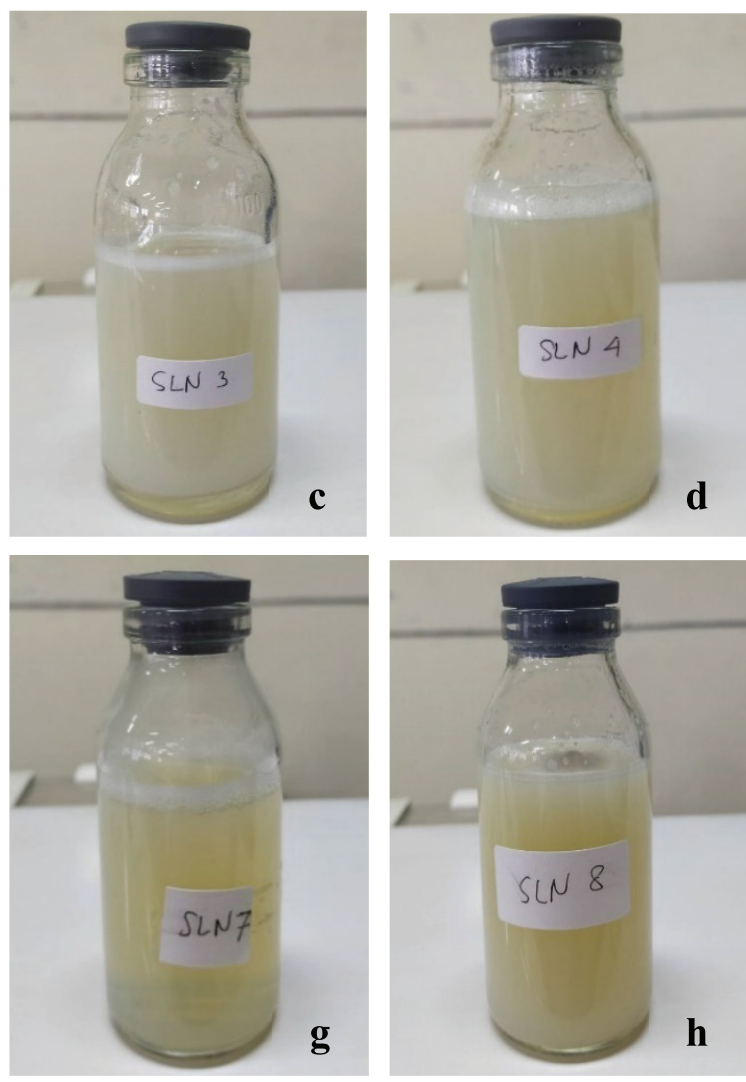
$45,60,90,120$, and 180 minutes of each medium and then replaced immediately with new media at the same volume to maintain sink conditions. The BSA content in the dissolution medium was analyzed using the Lowry protein assay. The absorbance was measured at a wavelength of $750 \mathrm{~nm}$ using a microplate reader (VersaMax, Chattanooga, TN). The BSA concentration was calculated using a standard calibration curve.

\section{RESULTS AND DISCUSSION}

\section{Colyophilization BSA with inulin}

Colyophilization is a process of protecting the BSA from conformational changes and denaturation during storage and passing through the GI tract. Colyophilization is carried out by coating the BSA protein with inulin. The ratio of the concentration of BSA and inulin is $1: 2.5$. From the experimental results, we obtained $32 \mathrm{mg}$ of BSA-inulin containing $10 \mathrm{mg}$ of BSA. The addition of inulin to BSA by colyophilization can increase protein stability and decrease denaturation caused by conformational change. Inulin as a protein protectant can prevent the unfolding of proteins (Furlán et al., 2010).

\section{Preparation of BSA-SLN}

The preparation of BSA-SLN uses the double-emulsion method. From the experimental results, it was found that the appearance of the SLN is a white-yellow, odorless, suspensionlike solution, as shown in Figure 1.

h

Figure 1. BSA--SLN preparation from formulations 1-8. 
Table 2. Particle size, PDI, zeta potential, and entrapment efficiency of BSA-SLN.

\begin{tabular}{ccccc}
\hline Formula & Particle size $(\mathbf{n m})$ & iPDI & Zeta potential $(\mathbf{m V})$ & Entrapment efficiency $(\%)$ \\
\hline F1 & 112.5 & 0.248 & -28.5 & 59.65 \\
F2 & 114.1 & 0.423 & -22.8 & 76.29 \\
F3 & 100.4 & 0.312 & -23.5 & 64.45 \\
F4 & 102.1 & 0.349 & -26.1 & 78.69 \\
F5 & 186.8 & 0.381 & -34.3 & 71.17 \\
F6 & 100.4 & 0.394 & -30.3 & 78.21 \\
F7 & 188 & 0.578 & -27.9 & 42.21 \\
F8 & 94.24 & 0.232 & -30.5 & 32.77 \\
\hline
\end{tabular}

\section{Preliminary characterizations of BSA-SLN}

\section{Particle Size Distribution}

The particle size distribution is measured by a particle size analyzer and seen at the $\mathrm{Z}$-Ave value. The $\mathrm{Z}$-Ave value is the average value of the particle size in the sample. The distribution of particle sizes ranges from $94.24 \mathrm{~nm}$ to $186.8 \mathrm{~nm}$ as can be seen in Table 2. This result proves that, from the F1 to F8 formulae, all have the ideal size for the SLN, which is in the range of 50-1,000 $\mathrm{nm}$. The increase of Tween 80 as a surfactant leads to a decrease in particle size and PDI due to reduced interfacial tension by a higher concentration of surfactant. The addition of soy lecithin as a cosurfactant can also decrease the mean particle size by stabilizing emulsion (Niculae et al., 2013). Formula 4 (F4) shows the best result of particle size measurement with $1.5 \%$ Tween 80 and $0.25 \%$ soy lecithin. Previous research showed that a smaller PDI (less than 0.7) indicates that the SLN has homogenous particle distribution (Trinovita et al., 2019). All the formulae tested in this research proved to achieve the ideal PDI for the SLN and therefore show that the SLN is distributed homogeneously.

\section{Zeta Potential}

Zeta potential is the electrical potential between the medium and interface of the fluid attached to the particle. Suppose the absolute value of the zeta potential is too high. In that case, the system deflocculates due to increased repulsion and cake dispersion. Suppose the zeta potential decreases below a particular value. In that case, attractive forces exceed the repulsive forces so that the particles will unite. In general, the zeta potential value of an emulsion is $+/-30 \mathrm{mV}$. Based on Table 2, it is found that the zeta potential value of the formula varies from $-22.8 \mathrm{mV}$ to $-34.3 \mathrm{mV}$. According to previous research, a zeta potential greater than $+30 \mathrm{mV}$ or $-30 \mathrm{mV}$ stipulates the excellent stability of the dispersion. This strongly indicates that all formulae of the SLN could be more stable (Chandran et al., 2018).

\section{Entrapment Efficiency of SLN}

The entrapment efficiency value is the ability of the matrix to trap the protein. The measurement of entrapment efficiency is carried out indirectly by calculating the amount of BSA that is not trapped. The value of entrapment efficiency can be seen in Table 2. From the observations, the most considerable SLN's entrapment efficiency is F4, which is $78.69 \%$. Greater entrapment efficiency can be obtained by increasing the concentration of surfactant to

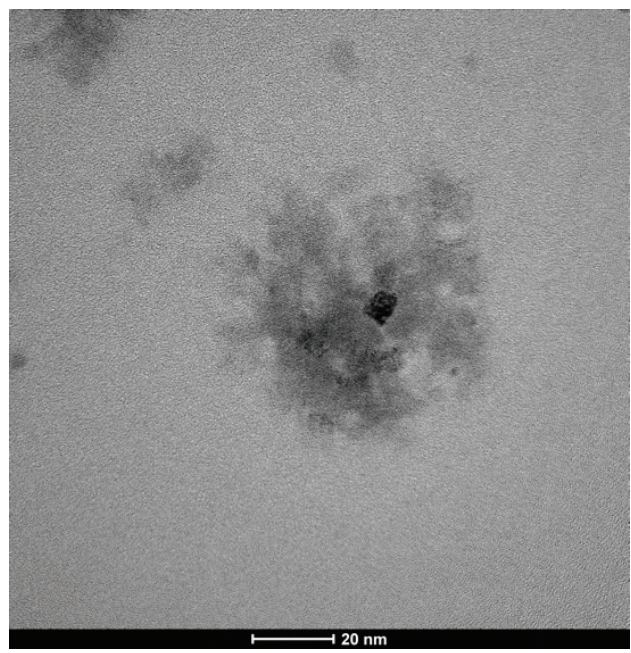

Figure 2. TEM of the optimized formula (F4 SLN).

improve BSA's stability and emulsifying capacity in the SLN system (Trinovita et al., 2019). Double-emulsification methods were found to increase drug solubility and entrapment efficiency (Ngwuluka et al., 2017). This research proved that the F4 SLN provides high entrapment efficiency, which can load a higher protein concentration.

\section{Final characterizations of BSA-SLN}

After conducting preliminary characterizations of BSA-SLN, the optimum formula was obtained based on the best initial descriptions, namely, F4. Furthermore, F4 preparation was evaluated for further tests, such as particle morphology and in vitro drug release studies.

\section{Particle morphology}

The particle morphology of the SLN was obtained from transmission electron microscopy (TEM). The results of the TEM of F4 can be seen in Figure 2. The SLN particles consist of a hydrophobic core with a surfactant monolayer layer based on the test results. The inside of the core contains proteins that are dispersed in a lipid matrix. The SLN's morphological characteristic, almost spherical with a smooth surface, was observed using a TEM photograph. Further, no precipitation of BSA was observed, indicating the SLN was stable (Kesharwani et al., 2016). 
Table 3. Cumulative drug release of SLN in $\mathrm{HCl}$, PBS 7.4, and PBS $6.8(n=3)$.

\begin{tabular}{lcc}
\hline Medium & Times (minute) & $\begin{array}{c}\text { \% Average cumulative } \\
\text { drug release }\end{array}$ \\
\hline HCl pH 1.2 & 15 & $0.00 \% \pm 0.00 \%$ \\
& 30 & $2.08 \% \pm 1.84 \%$ \\
& 45 & $7.74 \% \pm 6.94 \%$ \\
Phosphate buffer pH 7.4 & 60 & $12.58 \% \pm 6.74 \%$ \\
& 90 & $21.81 \% \pm 9.85 \%$ \\
& 120 & $25.97 \% \pm 4.91 \%$ \\
& 135 & $39.54 \% \pm 7.36 \%$ \\
& 150 & $47.37 \% \pm 9.53 \%$ \\
& 180 & $51.81 \% \pm 8.30 \%$ \\
& 210 & $56.85 \% \pm 9.77 \%$ \\
& 240 & $59.65 \% \pm 10.91 \%$ \\
& 300 & $63.73 \% \pm 10.72 \%$ \\
& 315 & $69.26 \% \pm 9.55 \%$ \\
& 330 & $77.93 \% \pm 8.92 \%$ \\
& 345 & $84.36 \% \pm 5.16 \%$ \\
& 360 & $88.64 \% \pm 6.22 \%$ \\
& 390 & $92.00 \% \pm 5.57 \%$ \\
420 & $97.49 \% \pm 3.79 \%$ \\
& 480 & $100.94 \% \pm 4.35 \%$ \\
& & $102.93 \% \pm 3.19 \%$ \\
\hline
\end{tabular}

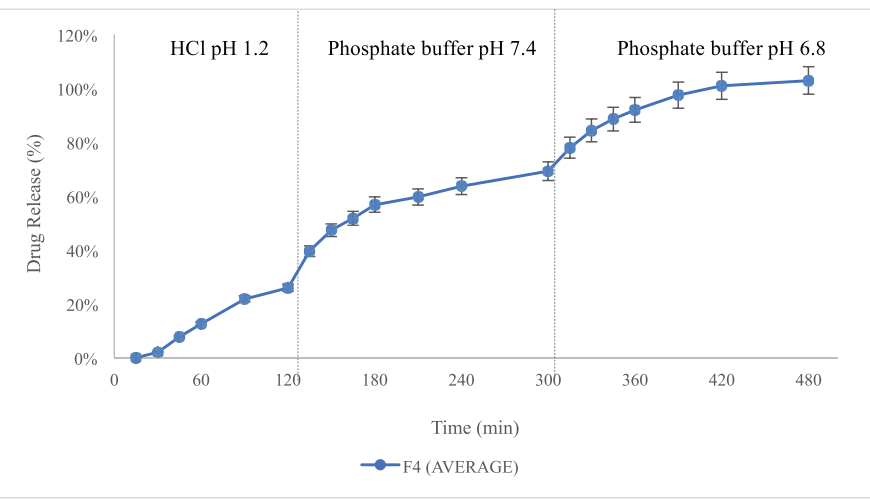

Figure 3. Cumulative drug release profile of F4 SLN. Data are expressed as mean $\pm \mathrm{SD}(n=3)$. $\mathrm{HCl}$ media $\mathrm{pH} 1.2(0-120$ minutes $)$; phosphate buffer $\mathrm{pH} 7.2$ (120-300 minutes); and phosphate buffer $\mathrm{pH} 6.8$ (300-480 minutes).

\section{In Vitro Drug Release Studies}

Based on the research results shown in Table 3 and Figure 3, the SLN F4 formulation could deliver a maximum drug to the colon. $102.93 \% \pm 3.19 \%$ BSA was released from the system after 8 hours of release study in three different media. Therefore, the F4 SLN had a potential delivery system in enhancing protein absorption in the colon. However, drug release had begun to occur in the simulated gastric and small intestine fluids. The release of BSA in the SLN system of F4 showed initial burst release followed by a slow controlled release of proteins. The drug release study indicated that, using F4 SLN, 25.97\% \pm
4.91\% BSA was released in the $\mathrm{HCl}$ solution $\mathrm{pH} 1.2$ in the first 2 hours. These results can be caused by the imperfect coating of BSA--SLN with Eudragit S100. The addition of excipients such as sustained-release polymers or polysaccharides can be used to prevent premature release.

\section{CONCLUSION}

Altogether, it can be concluded that F4 showed the best formulation to obtain the optimal parameter in producing the SLN. Furthermore, the SLN coated with Eudragit S100 performed best to hold the drug release in the stomach and provide better BSA release in the colon condition $(102.93 \% \pm 3.19 \%)$.

\section{ACKNOWLEDGMENTS}

The authors would like to thank Universitas Indonesia for funding this research through the PUTI Grant with contract number NKB-1808/UN2.RST/HKP.05.00/2020.

\section{CONFLICT OF INTEREST}

The authors declare no conflicts of interest, financial or otherwise.

\section{AUTHOR CONTRIBUTIONS:}

All authors made substantial contributions to conception and design, acquisition of data, or analysis and interpretation of data; took part in drafting the article or revising it critically for important intellectual content; agreed to submit to the current journal; gave final approval of the version to be published; and agree to be accountable for all aspects of the work. All the authors are eligible to be an author as per the international committee of medical journal editors (ICMJE) requirements/guidelines.

\section{REFERENCES}

Akash MSH, Rehman K, Chen S. Polymeric-based particulate systems for delivery of therapeutic proteins. Pharm Dev Technol, 2015; 21(3):367-78

Chandran SP, Nachinmuthu KP, Natarajan SB, Mohammad G. Papain loaded solid lipid nanoparticles for colorectal cancer therapy. Curr Cancer Ther Rev, 2018; 14:75-87

Date AA, Hanes J, Ensign LM. Nanoparticles for oral delivery: design, evaluation and state-of-the-art. J Control Release, 2016; 240 : 504-26.

Elmowafy M, Ibrahim HM, Ahmed MA, Shalaby K, Salama A, Hefesha H. Atorvastatin-loaded nanostructured lipid carriers (Nlcs): strategy to overcome oral delivery drawbacks. Drug Deliv, 2017; 24(1):932-41.

Furlán LTR, Padilla AP, Campderrós ME. Inulin like lyoprotectant of bovine plasma proteins concentrated by ultrafiltration. Food Res Int, 2010; 43(3):788-96.

Irianti MI, Rahmasari R, Arifianti AE, Iswandana R. Noninvasive strategies for protein drug delivery: oral, transdermal, and pulmonary. J Appl Pharm Sci, 2020; 10(10):166-179.

Iswandana R, Irianti MI, Oosterhuis D, Hofker HS, Merema MT, de Jager MH, Mutsaers HAM, Olinga P. Regional differences in human intestinal drug metabolism. Drug Metab Dispos, 2018a; 46(12):1879-85.

Iswandana R, Putri KSS, Sandiata CE, Triani S, Sari SP, Djajadisastra J. Formulation of tetrandrine beads using ionic gelation method ca-pectinate coated $\mathrm{pH}$-sensitive polymers as colon-targeted dosage form. Asian J Pharm Clin Res, 2017; 10(10):90-5.

Iswandana R, Putri KSS, Wulandari FR, Najuda G, Sari SP, Djajadisastra J. Preparation of calcium alginate-tetrandrine beads using ionic gelation method as colon-targeted dosage form. J Appl Pharm Sci, 2018b; 8(5):68-74. 
Kesharwani R, Sachan A, Singh S, Patel D. Formulation and evaluation of solid lipid nanoparticle (SLN) based topical gel of etoricoxib. J Appl Pharm Sci, 2016; 6(10):124-31.

Lagassé HAD, Alexaki A, Simhadri VL, Katagiri NH, Jankowski W, Sauna ZE, Kimchi-Sarfaty C. Recent advances in (therapeutic protein) drug development. F1000Res, 2017; 6:113.

Lu L, Chen G, Qiu Y, Li M, Liu D, Hu D, Gu X, Xiao Z. Nanoparticle-based oral delivery systems for colon targeting: principles and design strategies. Sci Bull, 2016; 61(9):670-81.

Martins S, Sarmento B, Ferreira DC, Souto EB. Lipid-based colloidal carriers for peptide and protein delivery - liposomes versus lipid nanoparticles. Int J Nanomedicine, 2007; 2(4):595-607.

Ngwuluka NC, Kotak DJ, Devarajan PV. Design and characterization of metformin-loaded solid lipid nanoparticles for colon cancer. AAPS PharmSciTech, 2017; 18:358-68.

Niculae G, Lăcătuşu I, Badea N, Oprea $\mathrm{O}$, Meghea A. Optimization of lipid nanoparticles composition for sunscreen encapsulation. UPB Sci Bull B Chem Mater Sci, 2013; 75(3):79-92.

Rajpurohit H, Sharma P, Sharma S, Bhandari A. Polymers for colon targeted drug delivery. Indian J Pharm Sci, 2010; 72(6):689-696.

Rehman K, Akash MSH, Akhtar B, Tariq M, Mahmood A, Ibrahim M. Delivery of therapeutic proteins: challenges and strategies. Curr Drug Targets, 2016; 17(10):1172-88.
Shah NV, Seth AK, Balaraman R, Aundhia CJ, Maheshwari RA, Parmar GR. Nanostructured lipid carriers for oral bioavailability enhancement of raloxifene: design and in vivo study. J Adv Res, 2016; $7(3): 423-34$.

Trinovita E, Rachmawati M, Sutriyo S, Mun'im A. In vitro penetration activity of ionic liquid-Gnetum gnemon seed extract loaded solid lipid nanoparticles. J Appl Pharm Sci, 2019; 9(10):9-16.

Zhang W, Li X, Ye T, Chen F, Yu S, Chen J, Yang X, Yang N, Zhang J, Liu J, Pan W, Kong J. Nanostructured lipid carrier surface modified with Eudragit RS 100 and its potential ophthalmic functions. Int J Nanomedicine, 2014; 9:4305-15.

How to cite this article:

Iswandana R, Sutriyo S, Gunawan M, Larasati SA, Putri

FA. Colon-targeted protein delivery by using solid lipid nanoparticles. J Appl Pharm Sci, 2021; 11(09):118-123. 